\title{
Os enquadramentos da citadinidade: sobre os impactos da prática do skate de rua na cidade de São Paulo'
}

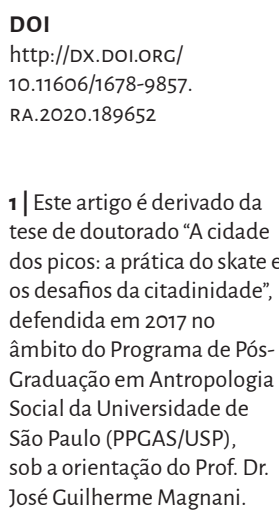

1 Este artigo é derivado da tese de doutorado "A cidade dos picos: a prática do skate os desafios da citadinidade", defendida em 2017 no âmbito do Programa de PósGraduação em Antropologia Social da Universidade de São Paulo (PPGAS/USP), sob a orientação do Prof. Dr. José Guilherme Magnani.

\section{Giancarlo Marques Carraro Machado}

O objetivo deste artigo é problematizar como a citadinidade skatista, entendida como uma maneira astuciosa, transgressiva e tática de se fazer a cidade, tem sido enquadrada de forma ambivalente por uma série de agenciamentos políticos e urbanísticos: ora visam combate-la, ora intentam impulsioná-la de modo um tanto estratégico a fim de atender a diversos interesses. Serão consideradas análises situacionais que revelarão os processos que permeiam uma citadinidade que preza pela materialidade da cidade e, não obstante, as relações com eventuais normatizações caras ao empresariamento urbano promovido pela parceria público-privada, a qual é sintomática de políticas de cunho neoliberais. Com efeito, ao tentar compreender como os skatistas fazem a cidade a partir de suas lógicas e vivências concretas, almeja-se desvencilhar as análises de perspectivas essencializantes, em prol de uma investigação centrada em processos que intercalam, embaralham e/ou superpõem diferentes planos, espaços, procedimentos e uma rede de agentes e saberes sociotécnicos.
Citadinidade, espaços urbanos, cidade, skate, Antropologia Urbana 


\section{INTRODUÇÃO}

A inserção dos skatistas na cidade de São Paulo é notadamente marcada pela coexistência de negociações, intervenções, disputas e conflitos. A modalidade skate de rua, foco do presente estudo, exprime uma experiência rítmica e fugaz em toda sorte de espaços, um ziguezagueante flanar pelas superfícies do urbano que revela a plasticidade de corpos em interação com equipamentos dos mais variados tamanhos, inclinações e texturas. É pelos picos - termo nativo que designa equipamentos urbanos (bancos, escadas, corrimãos etc.) que se tornam obstáculos para realização das manobras - que os skatistas fazem seus rolês ${ }^{2}$, se apropriam da cidade e se sentem estrangeiros (Simmel, 1983) em seus próprios contextos ${ }^{3}$. É pela possibilidade de encontrá-los inesperadamente que eles estão a filtrar tudo aquilo que observam em seus cotidianos.

Se por um lado tais atitudes aprazem os praticantes, por outro elas contrastam com os dissabores que acarretam na rotina conturbada da capital paulista: a prática do skate de rua é intrusiva, produz barulho, traz danos a propriedades e, não obstante, põe em risco a integridade física de pedestres. Malgrado esses aspectos que a associam a algo marginal, os skatistas - homens, jovens, oriundos de classes populares e médias em sua maioria-, quando em ação também colocam em xeque determinados ordenamentos esperados por planejadores urbanos. À vista disso é possível considerar que as suas manobras, bem como as suas circulações, repolitizam o cotidiano de uma cidade muitas vezes caracterizada pela sua mercantilização: elas testam a vigilância de seus espaços, dão visibilidade a diferentes formas de segregação, subvertem normas de acessibilidade, esquivam-se de aparatos de controle, deixam, pois, em suspensão as fronteiras entre os centros e as periferias. Assim sendo, concordo com a antropóloga Teresa Caldeira (2012: 63) quando, ao analisar as ações de skatistas paulistanos, assevera que a "interferência no espaço público e circulação pela cidade estão reconfigurando o espaço público e afirmando a presença ativa desses grupos de jovens na São Paulo contemporânea".

Mas também é importante considerar que, embora revele o potencial citadino da metrópole, a presença dos jovens nos espaços urbanos - a depender do tempo e do local que ocupam, de suas motivações e sobretudo de seus respectivos marcadores sociais de diferenças (classe, gênero, raça etc.) - nem sempre é tolerada. Isto traz à tona eventuais criminalizações de suas práticas, além de dar margem para a proliferação de discursos que os tratam na condição de delinquentes. É o que exprimem muitas matérias jornalísticas que geralmente reduzem as suas ações e dinâmicas relacionais a uma provável desordem que contraria princípios de cidadania que são considerados como socialmente mais aceitáveis para uma possível boa convivência nas cidades. A cargo de exemplo, a matéria intitulada "Praça Roosevelt sofre com vandalismo, drogas e sujeira"', publicada pela revista Veja São Paulo em 2016, acusa os skatistas, bem como pessoas em situação de rua, usuários de drogas ilícitas e vendedores ambulantes,
2 | A noção de rolê revela uma circulação citadina guiada por uma série de perspectivas. Ela é muito evidente no cotidiano juvenil paulistano, sendo recorrentemente utilizada para designar formas de mobilidades características de certos universos pautados por ordens de consumo (rolezinhos em shopping Center), por cenas artísticas (grafite e pichação), musicais (funk ostentação, rap, punk etc.), dentre tantas outras. No caso do skate, os rolês são motivados por aquilo que chamei em uma pesquisa precedente de olhar skatista (Machado, 2011), expressão que reverbera a percepção que os praticantes possuem dos espaços e equipamentos urbanos.

3 De acordo com Simmel (1983), a mobilidade pelos espaços urbanos permite as pessoas experimentarem tudo por meio de diversas sensações que proporcionam certo estranhamento que as condicionam se sentirem estrangeiras em suas próprias cidades.

4 | "Praça Roosevelt sofre com vandalismo, drogas e sujeira”. Revista Veja SP. Disponível em: https://vejasp.abril.com. $\mathrm{br} /$ cidades/praca-rooseveltdegradacao-vandalismodrogas/. Acesso em 15/04/2019. 
pelo estado deplorável de uma imponente praça situada no centro metropolitano, a qual, segundo a revista, enfrenta um suposto abandono e depredação, além de estar pichada e infestada por ratos mesmo após a sua recente reurbanização. Deste modo, ao disputarem os espaços urbanos, os skatistas e muitos outros citadinos tornam-se, via de regra, sujeitos indesejáveis em virtude das apropriações audaciosas e descontroladas que fazem da dimensão física da cidade.

A prática desenfreada do skate de rua historicamente tem sido considerada um problema para as governanças urbanas paulistanas. Muito já se tentou para reduzir os conflitos que ela acarreta no cotidiano da cidade de São Paulo, desde a sua proibição pelo então prefeito Jânio Quadros, em 1988, até a criação de projetos de lei e frentes parlamentares a fim de regulamentar a sua propagação. ${ }^{5}$ Contudo, para delimitála em áreas reservadas, as medidas mais recorrentes por parte da prefeitura, por meio de diversas gestões, têm sido a construção de dezenas de pistas de skate, as quais podem ser encontradas em todas as regiões da cidade, e o incentivo à frente esportivizada do skate. ${ }^{6} \mathrm{Na}$ visão de alguns agentes políticos, conforme já demonstrei em pesquisas precedentes (Machado, 2014; 2017), tais medidas representam uma boa solução diante as intensas disputas pelos usos de equipamentos urbanos, afinal, a partir delas os skatistas teriam espaços reservados e adequados para o treinamento de suas manobras, não sendo necessário, pois, a utilização das ruas. Trata-se de uma tentativa de esportivização da citadinidade, isto é, uma forma de adestrá-los espacial, corporal e moralmente a fim de modular como os skatistas se inserem na cidade e a maneira como interagem com ela.

Embora haja um notável incentivo à prática esportiva do skate em pistas, os skatistas, sobretudo os praticantes da modalidade skate de rua, nem sempre as utilizam. O que é mais valorizado no universo de tal modalidade não é o confinamento da sociabilidade em um dado espaço tido como artificial, que apenas simula obstáculos encontrados nas ruas ${ }^{7}$, tampouco o mero treinamento de habilidades corporais, mas a circulação e a apropriação criativa de picos originais encontrados inesperadamente pela cidade. Assim, as lógicas dos skatistas possuem certos distanciamentos em relação àquelas que têm sido fomentadas por múltiplos agentes do poder público municipal. Enquanto os últimos priorizaram, ao longo do tempo, a construção de pistas e a promoção de eventos em bairros periféricos, para os primeiros, ao contrário, muitas das experiências socialmente almejadas e compartilhadas decorrem em equipamentos urbanos situados nas centralidades de São Paulo. ${ }^{8}$ Conforme afirmado veementemente por muitos interlocutores, "é na rua em que se anda de skate de verdade". Eis o depoimento que me fora concedido por um skatista:
5 | Para mais detalhes sobre as proibições do skate em São Paulo, ver Brandão (2014) e Machado (2017). Sobre as frentes parlamentares, em nível municipal e estadual, em defesa do skate, ver Machado (2017)

6 | De acordo com Brandão (2014: 45), há uma frente do skate que trilhou "os caminhos de uma esportivização, o que posteriormente resultou na organização de campeonatos, pistas específicas para esta prática e o surgimento de fábricas especializadas na produção e comercialização de skates e demais produtos que a ele passaram a ser associados, como roupas e equipamentos de proteção". O principal exemplo de tal rumo é a inclusão do skate como modalidade olímpica nas Olímpiadas de Tóquio, em 2020.

7| Muitos obstáculos disponíveis em pistas de skate simulam equipamentos urbanos encontrados nas ruas pelos skatistas, como escadas, corrimãos, bancos, quinas etc. As pistas de skate geralmente eram consideradas pelos interlocutores, praticantes da modalidade skate de rua, como "ruas artificiais".

8 | Para reflexões detidas sobre as implicações dos desdobramentos das centralidades paulistanas, vide Frúgoli Jr. (2000). 
ocupando um espaço por diversão, dando um significado para aquilo, dando vida ao espaço. Acho bom para o entorno, até mais do que para a gente. A gente só quer se divertir. Mas acho que cria uma atmosfera no lugar onde a gente ocupou, dá vida, e isso é importante não só para o skate, mas para as pessoas em geral (Klaus Bohms, skatista profissional, entrevista em 2014).

Há uma citadinidade propagada entre os skatistas que considera a vivência de experiências urbanas (rolês, busca por picos, sociabilidades, conflitos, subversão dos usos dos espaços e equipamentos, exercício da alteridade etc.) uma virtude a ser seguida. Isto posto, ao levar em consideração o cotidiano dos adeptos do skate de rua, o objetivo deste artigo é problematizar como a citadinidade, entendida aqui como uma maneira astuciosa, transgressiva e tática de se fazer a cidade (Agier, 2011; 2015; Certeau, 2009), tem sido enquadrada de forma ambivalente por uma série de agenciamentos políticos e urbanísticos: ora visam combatê-la, ora intentam impulsioná-la de modo um tanto estratégico e utilitarista a fim de atender a diversos interesses. Serão consideradas, por consequência, algumas análises situacionais ${ }^{9}$ que revelarão os processos que permeiam uma citadinidade que preza pela materialidade da cidade e, outrossim, as relações com eventuais normatizações caras ao empresariamento urbano promovido pela parceria público-privada, a qual é sintomática de políticas de cunho neoliberais. Com efeito, ao tentar compreender como os citadinos fazem a cidade a partir de suas lógicas e vivências concretas, bem como o jogo relacional entre estratégias e táticas (Certeau, 2009) ${ }^{10}$, almeja-se desvencilhar as análises de perspectivas essencializantes, que consideram a cidade como uma coisa ou uma norma, em prol de uma investigação centrada em processos ocorridos na última década que intercalam, embaralham e/ ou superpõem diferentes planos, espaços, procedimentos e uma rede de agentes e saberes sociotécnicos.

\section{SKATISTAS: “TROPA DE CHOQUE” DA GENTRIFICAÇÃO?}

Devido às suas melhores condições urbanísticas, as áreas centrais da cidade de São Paulo concentram uma multitude de picos demasiados almejados pelos skatistas adeptos da modalidade skate de rua. Nas novas centralidades paulistanas, sobretudo nos limites das avenidas Paulista, Faria Lima e Berrini, por exemplo, é onde estão dispostos aqueles mais cobiçados. As características tangíveis de tais avenidas favorecem a qualidade de equipamentos que são considerados obstáculos skatáveis. Mármore, metal, inox, concreto armado, madeira, dentre outras texturas favoráveis ao skate compõem a estética arquitetônica destas que podem ser tidas como algumas das paisagens de poder (Zukin, 2000) da cidade."

Para utilizarem os picos situados nessas áreas enobrecidas de São Paulo, os skatistas, conforme evidenciei etnograficamente em outra publicação (Machado, 2019), se valem de táticas sortidas com vistas a desafiar os dispositivos que tentam
9|Análise situacional é um modelo teórico e metodológico que se propagou sobretudo a partir da Escola de Manchester e sua teoria da ação. Para uma contextualização sobre a importância da Escola de Manchester, ver FeldmanBianco (2010) e Hannerz (2015) Por meio da análise situacional há que se considerar, conforme pontua Agier (2011: 73), que

“[...] não são os limites espaciais que definem a situação, mas o da interação". Assim, ao levá-la em conta, intento partir das seguintes recomendações deste antropólogo tendo em vista uma melhor compreensão de certas questões em torno da citadinidade skatista: a) deslocar o ponto de vista da cidade para os citadinos; b) deslocar a problemática do objeto para o sujeito da questão, logo, em vez de considerar "o que é a cidade?", atentar para "o que faz a cidade?".

10|Certeau (2009: 45) chama de "estratégia" "[...] o cálculo das relações de forças que se torna possível a partir do momento em que um sujeito de querer e poder é isolável de um 'ambiente'. Ela postula um lugar capaz de ser circunscrito de suas relações com uma exterioridade distinta. A nacionalidade política, econômica ou científica foi construída segundo esse modelo estratégico". O mesmo autor (Certeau, 2009: 45-46) denomina, ao contrário, "tática" "[...] um cálculo que não pode contar com um próprio, nem portanto com uma fronteira que distingue o outro como totalidade visível. A tática só tem por lugar o do outro. Ela aí se insinua, fragmentariamente sem apreendê-lo por inteiro, sem poder retê-lo à distância. Ela não dispõe de base onde capitalizar os seus proveitos, preparar suas expansões e assegurar uma independência em face das circunstâncias".

11 As paisagens de poder, segundo Zukin (2000), são marcadas por uma estética sintomática de certas pretensões políticas e econômicas. São poderosas expressões das restrições estruturais de uma cidade. 
controlar os usos e as apropriações que deles podem ser feitas. Muitos interlocutores declararam não se render facilmente mesmo diante de todas as parafernálias de vigilância, da presença de seguranças e tampouco das intervenções de policiais e guardas metropolitanos: todos os elementos que visam impossibilitar a prática do skate se tornam obstáculos que devem ser vencidos por meio de suas manobras. Deste modo, é importante reiterar que o skate de rua implica não apenas técnicas corporais, mas artimanhas relacionais que devem ser acionadas a fim de conquistar um espaço ou um equipamento, seja público ou privado, ainda que por breves minutos.

As situações ocorridas no Beco do Valadão são sintomáticas dessas constatações. Os skatistas se apropriaram de uma extensão da calçada da Avenida Faria Lima, onde impera um dos metros quadrados mais caros da metrópole, numa estreita área localizada entre dois prédios empresariais. Lá imprimiram as suas próprias lógicas de ocupação sobre um espaço que se encontrava praticamente obsoleto. O Beco do Valadão, forma como era nomeado pelos interlocutores, tornou-se uma espécie de refúgio citadino em meio a uma paisagem de poder. Os skatistas deixaram uma série de marcas para afirmar que o local, embora também pudesse comportar inúmeras outras práticas e usos, é um pico ocupado regularmente por eles: paredes grafitadas, obstáculos construídos de maneira improvisada, parafinas espalhadas em vários cantos, materiais considerados como entulhos dispostos pelo chão, dentre outros elementos significativos que confirmam as suas presenças. Ali eles se reuniam cotidianamente e provocavam, com efeito, um contraste diante a lógica do trabalho e do consumo que impera na avenida. As suas presenças, circulações e manobras irritavam muitas das demais pessoas que passavam pelas calçadas da Avenida Faria Lima, as quais, como percebi no decorrer do trabalho de campo, não hesitavam em olhar com reprovação e até em xingar esses jovens que, segundo dadas perspectivas, estariam "fora do lugar". Os ordenamentos esperados para esta paisagem de poder são, então, subvertidos, remodelados e agenciados de maneiras díspares, e os skatistas, por sua vez, não raro são tratados como sujeitos indesejáveis pelos desconfortos que causam, sendo, por isso, combatidos e repelidos da avenida que parece ser gerenciada como uma mera mercadoria. ${ }^{12} \mathrm{~A}$ repulsa à presença dos skatistas manifesta-se de diferentes formas, seja por meio de abordagens policiais, pela implementação de dispositivos arquitetônicos que visam obstruir as suas manobras em certos equipamentos e também por outras estratégias pensadas para as calçadas da Avenida Faria Lima com a intenção de gentrificá-las. ${ }^{13}$ É o que ocorreu, por exemplo, na criação de um food park no Beco do Valadão, onde food trucks passaram a ocupar o mesmo espaço frequentado pelos skatistas numa clara tentativa de conter as suas manobras e de embelezar estrategicamente 0 local com a presença de carros bem equipados para a venda de comidas. Borden (2001: 231) salienta que, em situações como esta, "andar de skate, no entanto, não oferece nenhuma contribuição, visto que os skatistas utilizam os espaços sem se envolver com atividades produtivas" (tradução minha). A iniciativa seria, desta forma, uma maneira $\mathbf{1 2}$ | Sobre a produção da cidade como mercadoria, ver, dentre outros, Arantes, Vainer \& Maricato (2000).

13 | De acordo com Frúgoli Jr. e Sklair (2009: 120), o conceito de gentrificação (gentrification) se refere, em linhas gerais, à "criação de áreas residenciais para classes médias e altas em bairros de áreas urbanas centrais, articulados a processos de controle ou expulsão de setores das classes populares, num processo também assinalado pelo desempenho de determinados estilos de vida e de consumo, produzindo mudanças da composição social de um determinado lugar, bem como tipos peculiares de segregação socioespacial e de controle da diversidade". No entanto, tal conceito não se resume apenas a esses processos. Para uma discussão geral acerca do conceito de gentrificação, vide Harvey (1996), Featherstone (1995), Smith (1996), Zukin (2000), Bidou-Zachariasen (2006), etc. Para análises acerca da gentrificação em contexto nacional, ver, dentre outros, Leite (2006) e Frúgoli Jr. e Sklair (2009). Já para mais detalhes sobre as controvérsias em torno de sua polissemia, ver Rubino (2003). 
de fragmentar um espaço e de substituir jovens que pouco se envolvem em lógicas de consumo - e que também são acusados de fazer algazarra, atropelar pedestres e destruir equipamentos - por algo mais desejável, qual seja, uma prática comercial bem aceita por aqueles que trabalham nos tantos escritórios dispostos ao longo da avenida. Embora a tentativa tenha sido em vão - visto que skatistas e donos de food trucks entraram em consenso para compartilhar o espaço do Beco do Valadão ${ }^{14}$ - tal situação reverbera como o controle político e urbanístico das paisagens de poder - os quais muitas vezes são marcados por perspectivas neoliberais e pela articulação entre os parceiros da exclusão (Fix, 2001), ou seja, entre agentes ligados ao capital e ao Estado - preza menos pelos usos citadinos e mais pela mercantilização e enobrecimento de seus espaços a fim de fomentar o empresariamento urbano (Harvey, 1996). ${ }^{15}$

Essas constatações a respeito da prática do skate de rua não implicam, todavia, que os skatistas estão a todo o momento sendo tratados como sujeitos indesejáveis. A repulsa às suas presenças, conforme expresso acima, ocorre sobretudo em áreas enobrecidas da cidade. Já em outras áreas, como aquelas consideradas degradadas ou marcadas por ocupações populares, ou ainda em pórticos ${ }^{16}$ (Magnani, 2012), as suas inserções geralmente são toleradas e, em situações específicas, até mesmo estimuladas com vistas a atender certas pretensões de um estratégico controle socioespacial. ${ }^{17}$ Recordo-me, pois, de uma conversa estabelecida com um skatista no Vale do Anhangabaú, quando do trabalho de campo realizado para uma pesquisa anterior (Machado, 2011), que ilustra esta assertiva. Na ocasião o interlocutor Tiago Garcia comentou como o poder público municipal, sob a égide do então prefeito Gilberto Kassab (na época filiado ao DEM, em sua gestão de 2006 a 2008), vinha tratando a prática do skate realizada no local:

De vez em quando o prefeito resolve falar que não pode [andar de skate no Vale do Anhangabaú]. Um tempo atrás, Kassab falou que não podia. Aí ele começou a prestar atenção que aonde tem cara andando de skate, não tem muitos caras de rua mesmo. Uma época atrás no "Vale", os caras [os policiais] começaram a mandar embora os caras da cracolândia e os caras [usuários de crack] começaram a migrar para cá. Aí ficavam os caras fumando pedra, maconha o dia inteiro. Eos caras [agentes do poder público, policiais] começaram a perceber que onde tem a galera de skate, esses caras não ficam muito perto. Então é melhor ter skatista que droga! O skate meio que dá uma limpada! (Tiago Garcia, skatista profissional e empresário, entrevista em 2010. Grifos meus).

O caso acima, embora fizesse referência à prática do skate no Vale do Anhangabaú, associava-se, numa escala mais ampla, a um campo de relações que se desdobrava desde a Luz, bairro situado na região central frequentemente marcado, segundo Frúgoli Jr. e Spaggiari (2010), por duas representações recorrentes: a de "bairro cultural" e a de "cracolândia". No que toca a esta última representação, "cracolândia"18, os autores ressaltam, inspirados na perspectiva de Perlongher (2008), que ela constitui $\mathbf{1 4}$ | Certa vez, em 2017, tive a oportunidade de acompanhar uma negociação entre o skatista e advogado Gabriel Campello e o dono de um food truck. Ambos dialogaram acerca do espaço do Beco do Valadão e firmaram uma série de acordos a fim de se ajudarem e de compartilharem os usos do mesmo local. Esta e outras constatações permitem relativizar como certas práticas de gentrificação nem sempre impõem segregações concisas entre diferentes mundos sociais. Há, portanto, uma complexidade sintomática das dinâmicas relacionais, que somente podem ser compreendidas por vias etnográficas, que permitem colocar em xeque a efetividade de determinadas pretensões políticas e urbanísticas.

No caso do Beco do Valadão a tentativa de conter os skatistas foi minguada por este acordo não previsto entre eles e os food trucks, como já mencionado nesta nota.

15 Segundo Harvey (1996), noção de empresariamento urbano é uma estratégia das governanças urbanas a fim de estimular o desenvolvimento econômico por meio de uma postura empreendedora dos espaços urbanos. Tal postura é marcada pela parceria público-privada e se caracteriza por uma série de intervenções na cidade que culminam, por vezes, em segregações diversas.

16 De acordo com Magnan (2012), pórticos podem ser entendidos como marcos ou vazios urbanos.

17| Em vários espaços públicos da cidade a prática do skate de rua ocorre sem nenhum tipo de empecilho. Éo caso, por exemplo, de locais conhecidos pelos skatistas como Praça Brasil (Zona Leste), Praça Dina e Praça do Morumbi (Zona Sul), Praça Abelardo Rocas (Zona Oeste), dentre tantos que resguardam picos muito utilizados por eles.

18 | Para uma contextualização sobre a cracolândia paulistana, ver Rui (2014). 
uma espécie de territorialidade itinerante caracterizada pelo consumo de crack, posto que se situa numa certa área urbana, embora esteja sujeita a deslocamentos "mais próximos ou mais distantes, a depender do tipo de repressão ou intervenções exercidas, além das dinâmicas de suas próprias relações internas" (Frúgoli Jr. e Spaggiari, 2010: 3).

As gestões de Gilberto Kassab (prefeito em exercício entre 2006 e 2012) ${ }^{19}$ foram responsáveis por elaborar e por tentar implementar o projeto municipal intitulado Nova Luz, decretado em 2007, o qual visava uma série de intervenções urbanas - dentre elas, demolições de sobrados, extinção de cortiços e fechamento de hotéis em mau estado de conservação -, tendo em vista a valorização imobiliária de um perímetro situado no bairro da Luz. Somam-se a essas intervenções algumas operações policiais vigentes na "cracolândia", como a Operação Limpa (ocorrida a partir de 2005) e a Ação Integrada Centro Legal (instituída em 2009), que propunham banir a presença de usuários de crack em determinados espaços da região. Em razão das repressões que Ihes eram direcionadas, tais usuários dispersaram-se para muitas outras áreas do centro metropolitano, dentre elas, o Vale do Anhangabaú, um dos principais picos de skate de São Paulo.

Deste modo, a fala de Tiago Garcia pode ser melhor compreendida se levarmos em conta as intervenções urbanas e as operações policiais que vinham ocorrendo no bairro da Luz. A prática do skate havia se tornado, nesse sentido, estratégica no combate aos usuários de crack que de lá migraram para o Vale do Anhangabaú. As declarações proferidas pelo skatista ressoam, à vista disso, como intenções políticas e urbanísticas eventualmente se utilizam de uma citadinidade com vistas a combater outras que são ainda mais indesejáveis. Por ser um espaço de sociabilidade e de manobras para os skatistas, as suas presenças regulares em tal espaço público poderiam contribuir, segundo a perspectiva do interlocutor, para "dar uma limpada" no Vale do Anhangabaú, afinal, conforme também revela, era "melhor ter skatista que droga!". 20

A percepção do interlocutor também pode ser articulada a alguns processos que se tornaram evidentes ao longo da gestão do prefeito Fernando Haddad (PT, 2013-2016). A sua gestão prezou sobremaneira pela dimensão esportiva do skate ao se articular com as entidades que lhe são representativas (como Federação Paulista de Skate e Confederação Brasileira de Skate), ao manter a Coordenadoria de Esportes Radicais no âmbito da Secretaria de Esportes, Lazer e Recreação (SEME), ao apoiar a realização de determinados eventos e ao construir novas pistas públicas na cidade. No entanto, apesar desse notável enquadramento do skate como esporte em muitas de suas ações,

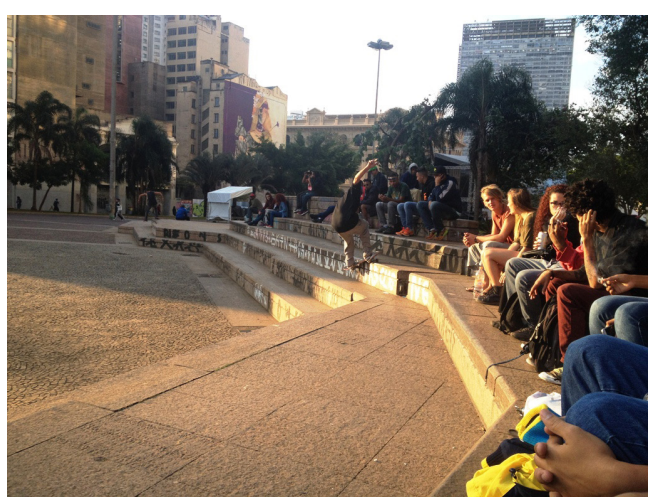

Imagem 1: Skatista em ação no Vale do Anhangabaú. Vários outros citadinos, sendo estes não skatistas, estão sentados nos demais degraus, compartilhando, pois, o mesmo espaço (foto por Ciancarlo Machado)
19| Cilberto Kassab foi prefeito entre os anos de 2006 e 2008 (filiado ao DEM) e entre 2009 e 2012 (filiado ao PSD).

20|A iniciativa surtiu pouco efeito. Conforme constatado etnograficamente (Machado, 2011), os skatistas muitas vezes possuíam relações de aproximação com aqueles que, em tese, deveriam combater, ou seja, citadinos considerados por dadas perspectivas como "poluidores" dos espaços urbanos (como tais usuários de drogas mencionados pelo interlocutor Tiago Garcia). Portanto, a pretensão de "limpar" o Vale do Anhangabaú, valendose da presença regular dos skatistas no local, não foi eficaz. Sobre os sentidos da noção de poluição, bem como de sua associação com noções de impureza e perigo, a partir de um viés antropológico, ver Douglas (1976) 
considero oportuno ponderar que também houve certas iniciativas institucionais poucas, diga-se de passagem - que se valeram estratégica e situacionalmente da dimensão citadina de sua prática ${ }^{21}$. Para abordá-las, recupero, pois, os desdobramentos de uma polêmica ocorrida a partir da prática do skate na Praça Roosevelt.

A praça em questão tornou-se, após a conclusão de sua reforma em 2012, o principal ponto de encontro dos skatistas paulistanos. Eles a ocuparam espontaneamente, desfrutando, por conseguinte, de suas novas condições arquitetônicas, as quais se configuraram, segundo a ótica de muitos interlocutores, perfeitas para a realização de manobras. A intensidade com que a prática do skate era realizada no local culminou numa série de conflitos, dentre eles, um episódio truculento que envolveu skatistas e guardas metropolitanos. Estes últimos tentaram cessar a qualquer custo a utilização de um pico, a saber, um banco de madeira, com a prerrogativa de que o equipamento não era destinado ao skate. As diferentes leituras acerca dessa apropriação resultaram numa agressão dos guardas metropolitanos direcionada a alguns skatistas presentes na ocasião.

A fim de mediar o conflito e arrefecer as polêmicas - as quais ganharam repercussão midiática após a divulgação de suas imagens-, a Prefeitura de São Paulo, por meio da Subprefeitura da Sé, convocou uma reunião entre diferentes usuários e instituições envolvidas com a Praça Roosevelt. Em razão disso foram firmados uma série de acordos, dentre os quais a implementação de regras de convivência e ainda a delimitação de uma área específica para a prática do skate, local onde foi construído uma pista. Apesar de todas as regulamentações e consensos, os skatistas se mantiveram ocupando todos os espaços possíveis da Praça Roosevelt, contrariando, portanto, os ordenamentos espaciais e relacionais que eram almejados.

Diante o ocorrido, Marcos Barreto, então subprefeito da Sé, reconheceu publicamente a astúcia dos skatistas em ocupar os espaços urbanos e também declarou o interesse do poder público municipal em aproveitá-los para recuperar áreas consideradas degradadas do centro metropolitano de São Paulo. A Rede Brasil Atual, portal online de notícias, destacou o fato:

\footnotetext{
A prefeitura de São Paulo quer aproveitar o "ímpeto e o destemor" dos skatistas paulistanos para recuperar áreas degradas no centro da cidade. A proposta é simples: identificar locais abandonados na região e adaptá-los à prática do skate, instalando pistas e obstáculos que atraiam jovens dispostos a fazer manobras e se divertir em espaços públicos. (Tadeu Breda, 2013: $s / p)^{22}$.
}

Conforme ainda divulgado pela matéria, três áreas da região central foram préselecionadas para serem adaptadas à prática do skate de rua, quais sejam, Baixada do Clicério, Praça Júlio Mesquita e Viaduto do Café. ${ }^{23}$ Cabe ressaltar que todas essas áreas comumente são representadas por matérias jornalísticas como "degradadas",
21 | Embora tais iniciativas aproveitassem da dimensão citadina do skate, elas ainda assim nomeavam a sua prática como um "esporte" (provocando, pois, uma dissonância diante as experiências dos skatistas que contestam tal enquadramento).

22 Reportagem de Tadeu Breda para o portal Brasil Atual: "Prefeitura de SP quer usar skatistas para recuperar áreas degradadas do centro". Disponível em: http://www.redebrasilatual. com.br/cidades/2013/04/ prefeitura-quer-usarskatistas-para-recuperarareas-degradadas-do-centro. Acesso em 08/04/2017

23 Apesar das promessas, poucas ações foram destinadas ao fomento da prática do skate nestas áreas. 
"abandonadas", como lugares "sem vida" que padecem pela presença poluidora de certos citadinos. O skate, segundo a perspectiva do agente político, poderia recuperálos por meio da frequência de seus praticantes e de suas manobras criativas realizadas nos espaços e equipamentos lá dispostos. O subprefeito Marcos Barreto enfatizou em entrevista à Rede Brasil Atual que:

Os skatistas ganham espaços propícios à prática do esporte e nos ajudam a reabilitar áreas que hoje viraram depósito de entulho. Todos saem ganhando, inclusive os demais moradores da capital: com novos espaços, os jovens deixarão de utilizar áreas inapropriadas para o skate, como a Avenida Paulista. (Breda, 2013: s/p)

A fala do subprefeito é bem categórica, visto que revela algumas das estratégias institucionais que perpassam os combates políticos e urbanísticos aos que são considerados, a depender do espaço, "indesejáveis". Nas áreas degradadas mencionadas, embora originalmente não tivessem sido planejadas para a prática do skate, a presença dos skatistas seria aceitável na medida em que as suas apropriações contribuíssem para dispersar demais citadinos por vezes tidos como marginais, como usuários de drogas ilícitas e pessoas em situação de rua. Já nas áreas enobrecidas da cidade, como a Avenida Paulista ou a Avenida Faria Lima, são os próprios skatistas que se tornam alvos de dispersão, posto que nelas as suas presenças e usos vernaculares se destoam das lógicas esperadas para as paisagens de tais contextos. ${ }^{24} \mathrm{Assim}$, em consonância com o frisado por Nolan (2003: 311):

\footnotetext{
Os espaços públicos são construídos de forma diferente, tanto fisicamente como socialmente, para diferentes fins, o que significa que atividades como o skate são sancionadas e encorajadas em alguns lugares, mas consideradas inadequadas e desencorajadas em outros.
}

Esse tipo de fomento institucional que se vale da prática do skate a fim de promover a renovação do uso de espaços urbanos considerados degradados é algo que já ocorre em cidades de outros países. Ocean Howell (2008), por exemplo, se deteve a analisar um caso emblemático ocorrido em Portland, estado de Oregon, nos Estados Unidos. Em tal cidade existia um espaço situado embaixo de uma ponte que podia configurar, ao levar em conta a perspectiva de Robert Park (1967), uma "região moral", isto é, um território residual, segregado, marcado neste caso por práticas e pessoas com desejos não convencionais, as quais, por isso, eram consideradas desviantes. Os skatistas, em meados da década de 1990, começaram não apenas a frequentar o referido espaço, mas também a construir, por conta própria e de maneira improvisada, alguns obstáculos de concreto nos limites do mesmo. A ação foi feita sem nenhum tipo de autorização formal. Como eles não encontraram impedimentos para tanto - afinal,

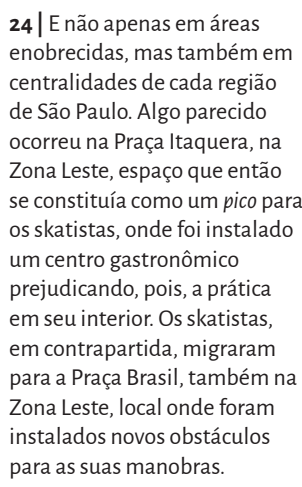

24 | E não apenas em áreas enobrecidas, mas também em centralidades de cada região de São Paulo. Algo parecido ocorreu na Praça Itaquera, na Zona Leste, espaço que então se constituía como um pico para os skatistas, onde foi instalado um centro gastronômico prejudicando, pois, a prática em seu interior. Os skatistas, em contrapartida, migraram para a Praça Brasil, também na Zona Leste, local onde foram instalados novos obstáculos para as suas manobras. 
tratava-se de uma área considerada em vias de degradação-, rapidamente surgiram novos obstáculos concomitantemente ao aumento do número de skatistas interessados em frequentar aquele que se tornou um dos picos mais atraentes da cidade.

Chamado de Burnside, em referência à ponte embaixo da qual se localiza, o espaço logo ganhou visibilidade em razão das intervenções efetivadas por aqueles que se tornaram seus novos frequentadores. ${ }^{25} \mathrm{~A}$ presença regular dos skatistas contribuiu para dispersar os demais citadinos que ali ocupavam, dentre eles, usuários de drogas ilícitas, prostitutas e pessoas em situação de rua, e para trazer uma segurança ao entorno que se revelou por meio da redução do roubo de automóveis e de arrombamentos de empresas vizinhas. Tudo isto culminou, com efeito, em novas imagens para o local e para a cidade de Portland. Burnside ganhou demasiada repercussão em matérias jornalísticas, além de constantemente figurar em fotos, vídeos e anúncios publicitários publicados na mídia especializada. Ademais, o pico tornou-se famoso a ponto de aparecer até numa edição do Tony Hawk's Pro Skater, série de jogos de videogame bastante difundida mundo afora.

Em decorrência destes impactos, conforme revela Howell (2008), representantes do Conselho Municipal de Portland reconheceram publicamente a atitude dos skatistas, a qual se coaduna a uma governança urbana de viés neoliberal, e, além disso, também regulamentaram a utilização, manutenção e gerenciamento do Burnside por parte deles. ${ }^{26}$ Nessas circunstâncias, amparando-se nestes e em outros casos analisados nos Estados Unidos, Howell (2008) considera que os skatistas, embora muitas vezes combatidos, também têm sido utilizados como parte de uma "tropa de choque da gentrificação" em virtude de serem os "olhos das ruas" capazes de dissuadir citadinos ainda mais "marginais", "deliquentes" ou "indesejáveis" que eles. ${ }^{27}$

Após este breve parêntese, o qual demonstrou as estratégias de cooptação política e urbanística de uma forma de citadinidade numa escala mais ampla, retomo o caso paulistano tendo como base as ações desenvolvidas no âmbito da gestão de Fernando Haddad. Além do posicionamento da Subprefeitura da Sé em prol da prática do skate em certos espaços urbanos considerados degradados, cabe destacar a atuação de agentes ligados à Coordenadoria de Promoção do Direito à Cidade e à Coordenadoria de Juventude, setores estes que reconheciam aos skatistas o direito de ocupar a cidade sem necessariamente se aterem a experiências que, via de regra, são enquadradas numa chave esportiva. ${ }^{28}$ Outra iniciativa que chamou a atenção na gestão supracitada foi a elaboração da cartilha "Espaços skatáveis: orientação para a adequação de espaços públicos abertos à prática de esportes urbanos", a qual fora concebida pela Secretaria de Urbanismo e Licenciamento. ${ }^{29}$

Tal documento pode ser considerado relevante na medida em que se propõe reconhecer o olhar skatista para produzir intervenções arquitetônicas na cidade. Trata-se, então, da institucionalização da construção de picos (nomeado pela cartilha como espaços skatáveis) nos mais variados espaços urbanos de São Paulo, algo inédito $\mathbf{2 5}$ | Burnside, contudo, não é o único exemplo de intervenção provocada pelos skatistas. Howell (2008) revela que este tipo de princípio, chamado por eles de do it yourself(DIY) - ou faça você mesmo - se difundiu por várias cidades do mundo.

26 | Cabe ressaltar que Burnside, após tantas intervenções por parte dos skatistas, ganhou inúmeros obstáculos a ponto de virar uma pista frequentada sobretudo por praticantes das modalidades banks e bowl.

27| Um caso parecido aconteceu na cidade do Rio de Janeiro. Segundo Diniz e Hermes da Silva (2017: 23) "No anfiteatro da Praça do Ó, o que se observava era a diversidade de frequentadores 'indesejados' - pessoas em situação de rua, prostitutas, traficantes de drogas e os próprios skatistas. A iniciativa dos skatistas de instalar nesse espaço objetos autoconstruídos para a prática do skate fez com que, paulatinamente, sua presença se fizesse mais numerosa, acarretando na dispersão dos demais 'indesejados".

28 | Tais coordenadorias promoveram inúmeros debates na Praça Roosevelt. Participei de alguns deles, ocasião em que constatei posicionamentos favoráveis por parte de determinados agentes do poder público no sentido de compactuar com o direito dos skatistas se apropriarem das ruas paulistanas.

29| Um dos principais envolvidos com a elaboração desta cartilha foi Rafael Murolo, skatista e arquiteto vinculado à SP Urbanismo, órgão da prefeitura municipal. Tal cartilha se embasou em diferentes pesquisas sobre a prática do skate nas ruas, dentre elas, a dissertação de minha autoria (Machado, 2011) 
no país. ${ }^{30} \mathrm{O}$ documento também se destaca por tentar aproximar e articular duas dimensões que permeiam a modalidade skate de rua: a esportiva e a citadina. O skate é, assim, definido como um esporte urbano, categorização que, segundo a perspectiva institucional vigente, abrange "esportes de rua, atividades como a prática de skate, patins, patinetes, bicicletas, parkour, entre outras, que utilizam o espaço urbano como suporte" (Cartilha espaços skatáveis, 2016: 3). Para mais, o documento ainda reconhece que o skate não é apenas um esporte urbano, mas também um elemento que compõe uma cultura urbana ou cultura de rua:

\footnotetext{
Além de esportes, esses podem ser considerados como elementos de uma "cultura urbana", ou uma "cultura de rua", com intensas relações com outras expressões, como a cultura hip-hop, por exemplo. São formas de convívio, de relações humanas e de interação com o espaço da cidade. A presença dessa prática nos espaços públicos abertos na cidade de São Paulo é notável, uma realidade urbana. Os praticantes apropriam-se de diversos elementos arquitetônicos construídos, como escadas, corrimãos, bancos, arquibancadas, planos inclinados e esplanadas com piso liso e uniforme (Cartilha espaços skatáveis, 2016: 3).
}

A proposta de construção de espaços skatáveis pode ser encarada como mais uma estratégia institucional com vistas a amenizar os impactos da prática do skate no meio urbano. Entretanto, em vez de combater as experiências de sua citadinidade e domesticar os praticantes num espaço delimitado e regrado, isto é, numa pista de skate - tal como muito tem sido feito -, a cartilha vislumbra considerar os usos criativos que eles fazem dos picos. Assim sendo, a fim de não os dificultar por meio da instalação de dispositivos arquitetônicos ou de demais formas de repressão, a presença dos skatistas é vista como transformadora dos espaços públicos, visto a competência em lhes dar maior vitalidade e abertura, além de ampliar a sua diversidade. Para estimulá-la, a cartilha recomenda meros ajustes pontuais em equipamentos urbanos para que eles se tornem mais seguros e resistentes à prática do skate. Cabe ressaltar que a pretensão não é a de construir obstáculos artificiais, tal como numa pista de skate, mas levar em consideração equipamentos originais com vistas a manter as suas condições de picos para os skatistas:

\footnotetext{
É possível imaginar soluções de projeto que acolham essas atividades como um elemento programático no projeto de espaços públicos abertos. Isso não significa projetar obstáculos, mas entender que diversos elementos arquitetônicos já são naturalmente desejados para manobras e que, com pequenas alterações no seu detalhamento, estes podem estimular ou conter a prática de esportes urbanos (Cartilha espaços skatáveis, 2016: 3).
}

Deste modo, a cartilha propõe que a prática do skate não necessariamente combata ou disperse demais usos citadinos - embora, contudo, isso possa ocorrer,
30| Algo similar foi elaborado pelo coletivo / love XV, composto por skatistas cariocas que se posicionam em prol da prática do skate na Praça $\mathrm{XV}$, no Rio de Janeiro. Para mais detalhes, ver Diniz, Silva e Campos (2013). 
como queria o subprefeito da Sé ao estimulá-la em espaços degradados -, mas que ela conviva e coexista com os mesmos em um espaço comum:

\footnotetext{
Os locais que permitem esse uso podem se tornar um ponto de encontro animado com público jovem, composto pelos praticantes, simpatizantes que contemplam as manobras e demais frequentadores. A presença dos skatistas transforma a realidade do lugar, de forma transitória, mas cotidiana. A "ativação" do entorno a esses espaços públicos abertos é sempre notável quando são apropriados para os esportes urbanos - aumento de fluxo de pessoas, mais encontros, interações, atividades, maior animação cultural (Cartilha espaços skatáveis, 2016: 3).
}

Para o alcance dos impactos urbanísticos pretendidos, a cartilha sugere três medidas que devem subsidiar a implementação do projeto. A primeira delas é a "setorização espacial", medida que consiste na definição de áreas que estimulem ou desencorajem a prática do skate, mas sem a necessidade de imposição de barreiras ou criação de espaços exclusivos. A setorização é uma maneira de promover uma leitura do espaço de modo a fomentar a interação e a simultaneidade de diversas práticas em seus limites sem que haja desentendimentos ou conflitos entre os presentes. A segunda medida, por sua vez, "orientação e fluxos", visa prever e orientar a permanência e circulação das pessoas nos espaços skatáveis. Promove-se assim um arranjo espacial que acarreta em maior segurança, evitando, com efeito, eventuais choques e atropelamentos, algo tão corriqueiro quando da prática do skate realizada em espaços urbanos. A terceira e última medida abarca os "elementos arquitetônicos e sua apropriação para manobras". Trata-se de diretrizes que norteiam a adequação, reforço e melhoria dos picos a fim de se tornarem alvos de múltiplos usos, seja por parte dos skatistas e de suas manobras ou por demais citadinos que queiram utilizá-los conforme suas vontades.

A cartilha em questão fora divulgada em dezembro de 2016, já ao fim do mandato de Haddad, fato que inviabilizou a sua incorporação nas ações do poder público municipal. Em razão disso não foi possível detectar empiricamente quais seriam os impactos da eventual implementação de espaços skatáveis em São Paulo. Apesar dessa limitação, a simples promoção da cartilha pode ser considerada sintomática da potência da prática do skate de rua na cidade. De modo geral, embora muito rechaçada, a resistência e a perspicácia dos skatistas vêm forçando posicionamentos multifacetados, por vezes controversos, por parte de diversos agentes ligados às governanças urbanas a fim de se aproximarem das experiências mais valorizadas do universo do skate. Assim, concordo com Telles (2015: 16) quando revela, ao se referir ao tratamento que vem sendo atribuído a várias práticas urbanas, que nos últimos anos,

\footnotetext{
[...] vêm se desenhando novas fronteiras sociais e territoriais, legais e políticas, seguindo os traços das mudanças engendradas pelos circuitos globalizados da economia urbana, bem como pelas redefinições dos modos de governo da cidade e seus espaços.
} 
As experiências citadinas da prática do skate de rua, não raro consideradas como destrutivas e agressivas, pouco a pouco se tornam alvo de interesse de uma agenda neoliberal de empresariamento urbano. Todavia, é importante atentar que tal aparente flexibilidade nem sempre é gratuita, posto que, segundo já aventara Zukin (1995), o esforço para o arranjo do espaço na cidade é um esforço de representação visual. Representação visual esta que possui implicações não apenas sociais, políticas e urbanísticas, mas também econômicas. Com efeito, a espetacularização que o skate promove da cidade vem se convertendo, inclusive, numa oportunidade rentável para as governanças urbanas e, sobretudo, para um corpo de agentes ligados ao mercado que investe em sua prática. ${ }^{31}$

\section{CONSIDERAÇÕES FINAIS}

O surgimento de pistas de skate não tem amenizado os conflitos que a prática do skate de rua ocasiona em variados espaços e equipamentos de São Paulo, sejam eles públicos ou privados. Uma considerável parte das ações institucionais que vem, há anos, sendo engendrada na cidade, releva apenas a sua dimensão esportiva em detrimento de outras mais. Todavia, os skatistas que estão efetivamente nas ruas - ou seja, aqueles que são alvos de tais ações - estão a ecoar que o skate não é permeado apenas pela ótica do esporte, mas também por lógicas citadinas que reivindicam maneiras astuciosas, por vezes subversivas, de se fazer a cidade.

Os adeptos da modalidade skate de rua circulam por toda São Paulo com olhares demasiados refinados a ponto de enxergar em sua materialidade probabilidades surpreendentes de usos. Eles se aproveitam dos mínimos detalhes, de equipamentos triviais, daquilo que poucos notam, das sobras do urbano. É, portanto, a cidade dos picos que mais Ihes interessa. É a partir de suas buscas que eles dão vitalidade às paisagens paulistanas e contribuem para tornar os espaços públicos, para parafrasear Joseph (2005), lócus de hibridização, excentricidades, acordos e instabilidades, revelando, outrossim, que eles não têm nada de orgânico.

Deste modo, conforme também já constatado em outra análise (Machado, 2019), os skatistas não abrem mão de seus rolês e da busca por picos repentinos a fim de utilizá-los a partir de suas próprias lógicas. Pouco importa onde estão dispostos e tampouco os dispositivos que regulam os seus usos. Os contratempos se convertem em obstáculos que devem ser superados astutamente. Eles embaralham a almejada convivência ordenada e põem em suspensão certos embelezamentos estratégicos de uma cidade gerenciada como mercadoria e voltada para práticas de cidadania que são englobadas sobretudo por lógicas de consumo. Muitas vezes a recusam tal como ela é. Incrédulos e teimosos que são a determinados ordenamentos e regulações, estes citadinos questionam as premissas que permeiam lugares próprios (Certeau, 2009) marcados por esperadas univocidades e estabilidades por meio de suas artimanhas, percepções e maneiras, e contribuem, assim, para a redefinição
31 | Para mais detalhes sobre a espetacularização da citadinidade a partir da pratica do skate, vide Machado (2017). 
do espaço como um lugar praticado (Certeau, 2009) com a apregoação de novas leituras e valores simbólicos.

Em razão disso, a citadinidade que permeia a prática do skate de rua, embora combatida, também vem sendo incorporada por pretensões políticas e urbanísticas. Nessas circunstâncias, ao mesmo tempo em que os skatistas se apropriam da cidade, as governanças urbanas, via alguns agentes específicos, vêm tentando se apropriar de suas experiências urbanas de acordo com seus próprios interesses e planejamentos. A citadinidade promovida pelo skate de rua tem se convertido, com efeito, em algo que se coaduna a uma espetacularização da cidade e ao controle de suas paisagens. Uma tática que se tornou uma estratégia, para utilizar termos de Certeau (2009), o que acaba sendo paradoxal: em muitos espaços, principalmente em áreas enobrecidas e em paisagens de poder (Zukin, 2000), os skatistas são tidos como poluidores, portanto, regularmente são combatidos; ao passo que em outros espaços, como em áreas consideradas degradadas, as suas permanências são toleradas ou até mesmo estimuladas a fim de que possam contribuir para o afastamento de outras apropriações e sujeitos ainda mais indesejáveis do que eles (usuários de drogas ilícitas, pessoas em situação de rua etc.). Tal "limpeza”, contudo, nem sempre se consolida, dada as aproximações situacionais que os skatistas estabelecem com aqueles que, ao que tudo indica, deveriam ser repelidos.

Neste artigo busquei revelar como a citadinidade é permeada por múltiplas configurações, enquadramentos, agenciamentos e contradições, além do jogo relacional entre estratégias e táticas que transcorre numa São Paulo vista a partir de uma perspectiva citadina. Foram evidenciadas, ainda, as assimetrias e as desigualdades que se processam em seus espaços urbanos e as maneiras como os skatistas se posicionam frente às mesmas. É possível concluir que ao ampliarem as suas possibilidades de usos, eles potencializam a produção de uma cidade vivida, sentida e em processo (Agier, 2011), tornando-a mais porosa ao se esquivarem de eventuais pragmatismos e dispositivos gestionários que tentam condicionar a vida urbana. Desta forma, esses jovens se articulam e agenciam suas próprias inserções na cidade, embora não deixem de desafiar as pretensões que visam torná-los mansos e inofensivos, não importando, inclusive, serem tratados como indesejáveis. É por meio de suas manobras, deslizes e equilíbrios que eles buscam visibilidade para afirmar as peculiaridades de uma forma de citadinidade.

Giancarlo Marques Carraro Machado é doutor em Antropologia Social pela Universidade de São Paulo". Retirar, portanto, "e mestre". As demais informações seguintes serão mantidas. Professor permanente do Programa de Pós-Graduação em Desenvolvimento Social da Universidade Estadual de Montes Claros (PPCDS/ Unimontes-MG) e do Departamento de Ciências Sociais da mesma instituição. É 
pesquisador vinculado ao Núcleo de Antropologia Urbana da Universidade de São Paulo (NAU/USP). Realizou estágio pós-doutoral no Departamento de Antropologia da Universidade de São Paulo (USP).

CONTRIBUIÇÃO DE AUTORIA: Não se aplica

FINANCIAMENTO: Fundação de Amparo à Pesquisa do Estado de São Paulo (FAPESP), processo 2012/23331-0.

\section{REFERÊNCIAS BIBLIOGRÁFICAS}

AGIER, Michel. 2011. Antropologia da cidade: lugares, situações, movimentos. São Paulo, Terceiro Nome.

ACIER, Michel. 2015. Do direito à cidade ao fazer-cidade. O antropólogo, a margem e o centro Mana: Estudos de Antropologia Social, v. 21, n. 3: 483-498. DOI: http://dx.doi. org/10.159o/0104-93132015v21n3p483

ARANTES, Otília; VAINER, Carlos; MARICATO, Ermínia. 2000. A cidade do pensamento único: desmanchando consensos. Petrópolis, Vozes.

BIDOU-ZACHARIASEN, Catherine. 2006. "Introdução". In: BIDOU-ZACHARIANSEN, Catherine (org.). De volta à cidade: dos processos de gentrificação às políticas de "revitalização" dos centros urbanos. São Paulo, Annablume, pp. 21-57.

BORDEN, lain. 2001. Skateboarding, space and the city: architecture and the body. Oxford, Berg.

BRANDÃO, Leonardo. 2014. Para além do esporte: uma história do skate no Brasil. Blumenau, Edifurb.

BREDA, Tadeu. 2013. "Prefeitura de SP quer usar skatistas para recuperar áreas degradadas do centro". Rede
Brasil Atual, 03/04/2013. Disponível em: http://www.redebrasilatual.com.br/ cidades/2013/04/prefeitura-quer-usarskatistas-para-recuperar-areas-degradadasdo-centro. Acesso em 08/04/2017.

CALDEIRA, Teresa Pires do Rio. 2012. Inscrição e circulação: novas visibilidades e configurações do espaço público em São Paulo. Novos estudos CEBRAP, n. 94: 31-67. DOI: http://dx.doi. org/10.1590/S0101-33002012000300002

CERTEAU, Michel de. 2009. A invenção do cotidiano: artes de fazer. 16. ed. Petrópolis, Editora Vozes.

DINIZ, Nelson; HERMES DA SILVA, Luciano. 2017. Contra-uso skatista de espaços públicos no Rio de Janeiro. Revista Eletrônica de Estudos Urbanos e Regionais, ano 7, n. 27: 1825. Disponível em: http://emetropolis.net/ system/artigos/arquivo_pdfs/000/000/202/ original/emetropolis27_art1.pdf?1485999132

DINIZ, Nelson; HERMES DA SILVA, Luciano; CAMPOS, Maicon Gilvan Lima. 2013. "A apropriação do espaço público pelo skateboarding no centro do Rio de Janeiro: o Coletivo I Love XV e a conquista do direito à cidade". Encuentro de Geógrafos de América Latina, 14, Anais, Lima. 
DOUGLAS, Mary. 1976. Pureza e

perigo. São Paulo, Perspectiva.

FEATHERSTONE, Mike. 1995.

Cultura de consumo e pós-modernismo.

São Paulo, Studio Nobel.

FELDMAN-BIANCO, Bela. 2010.

"Introdução". In: FELDMAN-BIANCO,

Bela (org.). Antropologia das sociedades contemporâneas: métodos. São Paulo, Editora UNESP, pp. 19-56.

FIX, Mariana. 2001. Parceiros da exclusão: duas histórias de construção de uma "Nova Cidade" em São Paulo: Faria Lima e Água Espraiada. São Paulo, Boitempo.

FRÚCOLI JR, Heitor. 2000. Centralidade em São Paulo: trajetórias, conflitos e negociações na metrópole. São Paulo, Cortez/Edusp.

FRÚCOLI JR., Heitor; SKLAIR, Jessica. 2009. "O bairro da Luz em São Paulo: questões antropológicas sobre o fenômeno da gentrification". Cuadernos de Antropología Social, n. 30: 119-136. Disponível em: http:// www.scielo.org.ar/pdf/cas/n30/n30a07.pdf

FRÚGOLI JR., Heitor; SPACGIARI, Enrico. 2010. Da cracolândia aos nóias: percursos etnográficos no bairro da Luz. Ponto..Urbe, n. 6: 1-26. DOI: https:// doi.org/10.4000/pontourbe.1870

HANNERZ, UIf. 2015. Explorando a cidade: em busca de uma Antropologia Urbana. Petrópolis, Editora Vozes.

HARVEY, David. 1996. “Do gerenciamento ao empresariamento: a transformação da administração urbana no capitalismo tardio". Espaço \& Debates, n. 39: 48-64.

HOWELL, Ocean. 2008. Skatepark as neoliberal playground: urban governance, recreation space, and the cultivation of personal responsibility. Space and culture, v. 11, n. 4: 475-496.
JOSEPH, Isaac. [1998] 2005. "A respeito do bom uso da Escola de Chicago". In VALLADARES, Lícia do Prado (org.). A Escola de Chicago: impacto de uma tradição no Brasil e na França. Belo Horizonte/Rio de Janeiro, Ed. UFMG/IUPER], pp. 93-128.

LEITE, Rogério Proença. 2006. “Margens do dissenso: espaço, poder e enobrecimento urbano". In: FRÚCOLI JR., Heitor; ANDRADE, Luciana Teixeira de; PEIXOTO, Fernanda Áreas (orgs.). As cidades e seus agentes: práticas e representações. Belo Horizonte; São Paulo, PUC Minas/Edusp, pp. 23-44.

MACHADO, Giancarlo Marques Carraro. 2011. De "carrinho" pela cidade: a prática do street skate em São Paulo. São Paulo, dissertação de mestrado, Universidade de São Paulo.

MACHADO, Giancarlo Marques Carraro. 2014. De "carrinho" pela cidade: a prática do skate em São Paulo. São Paulo, Editora Intermeios/FAPESP.

MACHADO, Giancarlo Marques Carraro. 2017. A cidade dos picos: a pratica do skate e os desafios da citadinidade. São Paulo, tese de doutorado, Universidade de São Paulo.

MACHADO, Giancarlo Marques Carraro. 2019. Mão na massa e skate no pé: práticas citadinas nas novas centralidades paulistanas. Anuário Antropológico, v. 44, n. 1: 285-305. DOI: https://doi.org/10.4000/aa.3523.

MAGNANI, José Guilherme Cantor. 2012. Da periferia ao centro: trajetórias de pesquisas em Antropologia Urbana. São Paulo, Terceiro Nome.

NOLAN, Nicholas. 2003. "The ins and outs of Skateboarding and transgression in public space in Newcastle". Australian Geographers, v. 34, n. 3: 311-327.

PARK, Robert. 1967. "A cidade: sugestões para a investigação do comportamento social no meio urbano". In VELHO, Otávio. (org.) O fenômeno urbano. Rio de Janeiro, Zahar, pp. 25-66. 
PERLONGHER, Néstor. 2008. O negócio do michê: a prostituição viril em São Paulo. São Paulo, Ed. Fundação Perseu Abramo.

PREFEITURA DE SÃO PAULO. 2016. “Espaços skatáveis: orientação para a adequação de espaços públicos abertos à prática de esportes urbanos". São Paulo: Secretaria de Gestão Urbana. Disponível em: http:// gestaourbana.prefeitura.sp.gov.br/wpcontent/uploads/2015/04/Cartilha-espacosskataveis.pdf. Acesso em 09/02/2017.

QUINTELLA, Sérgio. 2016. "Praça Roosevelt sofre com vandalismo, drogas e sujeira”. Revista Veja SP. Disponível em: https:// vejasp.abril.com.br/cidades/pracaroosevelt-degradacao-vandalismodrogas/. Acesso em 15/04/2019.

RUBINO, Silvana. 2003. "Gentrification: notas sobre um conceito incômodo". In SCHICCHI, Maria Cristina; BENFATTI, Dênio (orgs.). Urbanismo: dossiê São Paulo-Rio de Janeiro. Campinas/Rio de Janeiro, PUC-Campinas/Prourb-UFR].
RUI, Taniele. 2014. Nas tramas do crack: etnografia da abjeção. São Paulo, Terceiro Nome.

SIMMEL, Georg. [1908] 1983. "O estrangeiro". In: MORAES, Evaristo (org.). Sociologia: Simmel. São Paulo, Ática, pp.182-188.

SMITH, Neil. 1996. The new urban frontier: gentrification and revanchist city. Londres/Nova York, Routledge.

TELLES, Vera da Silva. 2015. Cidade: produção de espaços, formas de controle e conflitos. Revista de Ciências Sociais (UFC), v. 46, n. 1: 16-42.

ZUKIN, Sharon. 1995. The cultures of cities. Oxford, Blackwell.

ZUKIN, Sharon. 2000. "Paisagens urbanas pós-modernas: mapeando cultura e poder". In: ARANTES, Antonio (org.). O espaço da diferença. Campinas, Papirus, pp. 80-103.

Recebido em 20 de abril de 2020. Aceito em 18 de março de 2021. 
artigo | Giancarlo Marques Carraro Machado | Os enquadramentos da citadinidade: sobre os impactos da prática do skate de rua na cidade de São Paulo 